\title{
Financial Market Anomalies
}

Financial market anomalies are cross-sectional and time series patterns in security returns that are not predicted by a central paradigm or theory. The term anomaly can be traced to Kuhn (1970). Documentation of anomalies often presages a transitional phase toward a new paradigm.

Discoveries of financial market anomalies typically arise from empirical tests that rely on a joint null hypothesis - to wit, security markets are informationally efficient and returns behave according to a prespecified equilibrium model (e.g., capital asset pricing model (CAPM)). If the joint hypothesis is rejected, we cannot attribute the rejection to either branch of the hypothesis. Thus, even though anomalies are often interpreted as evidence of market inefficiency, such a conclusion is inappropriate because the rejection may be due to an incorrect equilibrium model. Some have argued that, once identified by researchers, the magnitude of financial anomalies will tend to dissipate as investors seek to profitably exploit the return patterns or because their discovery was simply a sample-specific artifact. Although this has happened for some of the findings discussed below (e.g., the weekend effect), most of the anomalies discussed continue to persist. The fact that so many of these patterns have persisted for decades suggests that they are not evidence of market inefficiencies. Rather, our benchmark models might be less than complete descriptions of equilibrium price formation.

The number of documented anomalies is large and continues to grow. The focus here will be on equity market anomalies, and on the subset whose existence has proven most robust with respect to both time and the number of stock markets in which they have been observed. We broadly classify the findings as being cross-sectional or time series in nature.

\section{Cross-Sectional Return Patterns}

Given certain simplifying assumptions, the CAPM states that the return on a security is linearly related to the security's non-diversifiable risk (or beta) measured relative to the market portfolio of all marketable securities. If the model is correct and security markets are efficient, security returns will on average conform to this linear relation.

Empirical tests of the CAPM first became possible with the creation of computerized databases of stock

prices in the U.S. in the 1960's. To implement the tests, researchers often estimate cross-sectional regressions of the form

$$
R_{i}=a_{o}+a_{1} \beta_{i}+\sum a_{j} c_{i j}+e_{i}
$$


where $\beta_{i}$ is the security's beta which measures its covariance with the return on the market and $c_{i j}$ represents security-specific characteristic $j$ (size, earnings yield, etc.) for security $i$. The CAPM predicts that the $a_{j}$, for $j>$ 1, are zero. Early tests supported the CAPM (e.g., significant positive values for $a_{1}$, insignificant values for $a_{j}$, for $j>1$ ). The explanatory power of beta came into question in the late 1970s when researchers identified security characteristics such as the earnings-to-price ratio and market capitalization of common equity with more explanatory power than beta.

This section presents a sample of the more important contributions in this area that collectively stand as a challenge for alternative asset pricing models.

\section{The Value Effect}

The value effect refers to the positive relation between security returns and the ratio of accountingbased measures of cash flow or value to the market price of the security. Examples of the accounting-based measures are earnings per share and book value of common equity per share. Investment strategies based on the value effect have a long tradition in finance and can be traced at least to Graham and Dodd (1940). Ball (1978) argues that variables like the Earnings-to-Price ratio (E/P) are proxies for expected returns. Thus, if the CAPM is an incomplete specification of priced risk, it is reasonable to expect that E/P might explain the portion of expected return that is compensation for risk variables omitted from the tests.

Basu (1977) was the first to test the notion that value-related variables might explain violations of the CAPM. He found a significant positive relation between E/P ratios and average returns for U.S. stocks that could not be explained by the CAPM. Reinganum (1981) confirmed and extended Basu's findings. Rosenberg, Reid and Lanstein (1985), DeBondt and Thaler (1987) and many others have documented a significant positive relation between returns and the Book-to-Price ratio (B/P). Researchers have also identified a significant relation between security returns and value ratios that use cash flow (earnings plus accounting depreciation expense) in place of earnings in the numerator of the ratio. The value effect in its many forms has been reproduced by numerous researchers for many different sample periods and for most major securities markets around the world (see Hawawini and Keim (2000) for a review).

Dividend yield, the ratio of cash dividend to price, has also been shown to have cross-sectional return predictability. Although similar in construction to the value ratios, the explanatory power of dividend yields is most often attributed to the differential taxation of capital gains and ordinary income as described in the after-tax asset pricing models developed by Brennan (1970) and Litzenberger and Ramaswamy (1979). 
Although a positive relation between stock returns and dividend yields has been documented in many studies, interpretation of the results as support for an after-tax pricing model has been controversial. Evidence on the dividend yield effect has been provided by Litzenberger and Ramaswamy (1979), Miller and Scholes (1982) and many others.

\section{The Size Effect}

The size effect refers to the negative relation between security returns and the market value of the common equity of a firm. Banz (1981) was the first to document this phenomenon for U.S. stocks (see also Reinganum (1981)). In the context of equation (1), Banz found that the coefficient on size has more explanatory power than the coefficient on beta in describing the cross section of returns. Indeed, Banz finds little explanatory power for market betas. Like the value effect, the size effect has been reproduced for numerous sample periods and for most major securities markets around the world (Hawawini and Keim (2000)).

\section{Interpretation of the Value and Size Effects}

The separately-identified value and size effects are not independent phenomena because the security characteristics all share a common variable - price per share of the firm's common stock. Indeed, researchers have shown a high rank correlation between size and price and between the value ratios and price, and others have documented a significant cross-sectional relation between price per share and average returns. To sort out the relative importance of the different variables, Fama and French (1992) (FF) estimate equation (1) with multiple value and size variables included as explanatory variables (see also Jaffe, Keim and Westerfield (1989)). FF find that B/P and Size provide the greatest explanatory power in describing the cross section of returns, and suggest that $\mathrm{B} / \mathrm{P}$ and Size are proxies for the influence of two additional risk factors omitted from the CAPM. In this context, the value and size variables can be viewed as capturing sensitivities to the omitted factors, and the coefficients multiplying the value and size variables $\left(a_{j}\right.$ in equation (1)) are estimates of the risk premia required to compensate for that exposure. ${ }^{1}$ Predicated on this interpretation, Fama and French (1993) propose a three-factor model to describe the time series behavior of security returns:

$$
R_{t}-r_{f, t}=\beta_{0}+\beta_{1}\left(r_{m, t}-r_{f, t}\right)+\beta_{2} S m B_{t}+\beta_{3} H m L_{t}+\varepsilon_{t}
$$

\footnotetext{
${ }^{1}$ A valid question is whether a characteristic like $\mathrm{B} / \mathrm{P}$ proxies for an underlying risk factor that is the determinant of expected returns or whether the characteristic itself is the determinant of expected returns. Daniel and Titman (1997) address this issue and conclude that security characteristics appear to be more important than the covariance of security returns with a factor related to the characteristic.
} 
where $R_{t}$ is the return on the asset in month $t, r_{f, t}$ is the monthly treasury bill rate, $r_{m, t}$ is the return on a valueweighted market portfolio, $S m B_{t}$ is a monthly size premium (Small stock return - Large stock return), $H m L_{t}$ is a monthly value premium (High $\mathrm{B} / \mathrm{P}$ return - Low $\mathrm{B} / \mathrm{P}$ return), and $\varepsilon_{t}$ is the error term. As constructed, $\mathrm{SmB}$ and $\mathrm{HmL}$ are zero net investment portfolios. If these three factors span all sources of common systematic co-movement in security returns, $\beta_{0}$ (“alpha”) will on average equal zero. The model has received much empirical confirmation and appears to explain numerous previously-reported incidences of anomalous cross-sectional return patterns (i.e., such effects have $\beta_{0}=0$ in equation (2)).

As mentioned above, the mean values of the three factors in model (2) can be interpreted as the premium or compensation earned by an investment position for unit exposure to each separate factor. The relative magnitudes of these factor premia are of economic interest. The market risk premium quantifies the return, in excess of a default-risk-free return, provided for investing in a broadly diversified portfolio as represented by the value-weighted market portfolio. Over the period 1927 to 2005 the average equity market risk premium in (2) is $0.64 \%$ per month. Utility-based asset pricing models have difficulty explaining an equity premium of this magnitude - either because the returns on default-risk-free bonds are too low, or the returns on equities are too high. This has been called the equity premium puzzle (Mehra and Prescott (1985)) and has generated an extensive literature trying to reconcile the theory and empirical evidence.

The mean risk premia associated with the size effect $(\operatorname{SmB})$ and the value effect $(H m L)$ should be zero if the CAPM is correct. Consistent with the research described above, $\operatorname{SmB}$ and $H m L$ are both positive. For the period January 1927 to December 2005 the monthly mean (t-value) is 0.25\% (1.99) for $\mathrm{SmB}$ and $0.45 \%$ (3.47) for $H m L$, and the correlation between the two premia is 0.14 . Figure 1 plots the time series of the intra-year monthly means of the two premia. The figure shows (i) both premia display substantial variability over time and (ii) the two series display a considerable common co-movement despite the low estimated correlation.

Regarding the first point, there are extended periods when the signs of the risk premia are reversed. This is particularly evident for the size effect - for extended periods in the 1950s and the 1980s large firms outperformed small firms, in contrast to other periods (1930s, 1940s, 1970s, and post 2000) when small stocks outperformed large stocks. Because the estimated magnitudes of the effects are sensitive to the period in which they are measured, it is important to distinguish between unconditional and conditional expected values for the effects. Further, it is relevant to ask whether the 79-year sample we have for the U.S. market (longer than in other developed equity markets) is long enough to capture the "long-run" magnitudes of such volatile 
effects. (The same caveat has been raised regarding the magnitude of the equity premium.)

Regarding the second point, the visual appearance of common co-movement between the series suggests the two effects are not entirely independent. This possibility is confirmed when the time series plots of $\mathrm{SmB}$ and $\mathrm{HmL}$ are decomposed into separate plots for January and February-to-December observations (figure 2). Much research has shown that the size and value effects are most pronounced in the month of January and this research will be discussed in more detail in the next section. For now, we limit discussion to the difference in the behavior of $\operatorname{SmB}$ and $H m L$ between January and February-to-December. First, the mean values for both premia are an order of magnitude larger in January than in February-December. Second, the correlation of 0.40 in January vs. 0.07 for February-to-December demonstrates the commonality between the two series in figure 1 arises mostly from their common behavior in January.

What explains the value and size effects? That both premia reflect some common element which manifests only in January is hard to reconcile with a risk compensation story. (Non-risk-based explanations of the January effect are discussed in the section on seasonal patterns in stock returns below.) Much recent research, nevertheless, has characterized the value premium as compensation for financial distress risk. Theoretical models have been developed in which such risk plays a central role, and value (high B/P) stocks accordingly earn higher equilibrium returns than growth (low B/P) stocks. Others have argued that the size effect is actually a liquidity effect in which small-cap stocks are less liquid than large-cap stocks and therefore provide correspondingly higher returns to offset the higher transactions costs (e.g., Brennan, Chordia and Subrahmanyam (1998)). Still others have suggested that the size and B/P results may be due to survivor biases in the databases used by researchers (e.g., Kothari, Shanken and Sloan (1995)).

One final hypotheses concerns measurement error in the estimated market betas used in the tests. Firms whose stocks have recently declined in price (e.g., many high B/P and small-cap stocks), in the absence of a concomitant decline in the value of the debt, have become more leveraged and, other things equal, more risky in a beta sense. Traditional estimation methods produce "stale" betas that underestimate "true" beta risk for such firms. Thus, B/P and size may be viewed as better instruments for "true" market beta risk than traditional estimates of beta, and the value and size effects are simply capturing the measurement error in the traditional beta estimates.

\section{The Prior Return or Momentum Effect}

Prior stock returns have been shown to have explanatory power in the cross section of common stock returns. Stocks with prices on an upward (downward) trajectory over a prior period of 3 to 12 months have a higher than expected probability of continuing on that upward (downward) trajectory over the subsequent 3 to 
12 months. This temporal pattern in prices is referred to as momentum. Jegadeesh and Titman (1993) show that a strategy that simultaneously buys past winners and sells past losers generates significant abnormal returns over holding periods of 3 to 12-months. The abnormal profits generated by such offsetting long and short positions appear to be independent of market, size or value factors and has persisted in the data for many years. To this end, Carhart (1995) estimates an extension of model (2) that includes a momentum factor (in addition to market, size and value factors) defined in the spirit of Jegadeesh and Titman as the difference in returns between a portfolio of "winners" and a portfolio of "losers." The coefficient on the momentum factor is positive and statistically significant, and cannot be explained by the other three factors. Finding a rational risk-related explanation for the momentum effect has proven difficult. A number of researchers have posited behavioral (psychology-based) explanations of momentum that rely on irrational market participants who underreact to news, but these models are hard to reconcile with psychology-based models of overreaction posited to explain the value premium (e.g., Lakonishok, Shleifer and Vishney (1994)).

\section{Time Series Return Predictability}

Consider a model of stock prices in which expected stock returns are constant through time (see Fama (1976) for discussion of this model and related tests of the behavior of stock prices). Much recent evidence suggests that expected returns are not constant, but contain a time-varying component that is predicted by past returns, ex ante observable variables, and calendar turning points. The following sections discuss this evidence.

\section{Predicting returns with past returns I: Individual security autocorrelations}

Much research finds that autocorrelations of higher-frequency (daily, weekly) individual stock returns are negative and that the autocorrelations are inversely related to the market capitalization of the stock. The exception is that the largest market cap stocks have positive autocorrelations for daily returns. The inverse relation between individual return autocorrelations and market capitalization is due to the influence of a bid-ask bounce in high frequency stock prices that may induce "artificial" serial dependencies into returns. Niederhoffer and Osborne (1966) find that successive trades tend to occur alternately at the bid and then the ask price, resulting in negative serial correlation in returns. This negative serial dependency is more pronounced for smaller stocks that have lower prices and, consequently, for which the bid-ask spread represents a larger percentage of price. Because of the high variance of individual stock returns, researchers find that past returns explain a trivial percentage of total return variability at high frequencies (typically less than 1 percent). And the predictability at high frequencies is economically insignificant: profits from trading strategies attempting to exploit the predictability in individual stocks are indistinguishable from zero. 


\section{Predicting returns with past returns II: Aggregate return autocorrelations}

Because of variance reduction obtained from diversification, aggregated or portfolio returns provide more powerful tests of return predictability using past returns. However, this increased power may be offset by upward-biased autocorrelations caused by the infrequent trading of securities in the portfolios (Fisher (1966)). This bias is more serious for portfolios of smaller-cap stocks that contain less-frequently traded stocks. In the U.S. and other global equity markets positive autocorrelations for high frequency portfolio returns range from 0.4 for small-cap stocks to 0.1 for large-cap stocks. Research has shown, however, that positive portfolio autocorrelations are not due to infrequent trading of the securities in the portfolio. Indeed, many researchers have reported statistically significant positive portfolio autocorrelations for return frequencies up to one month in the U.S., an interval over which virtually all securities will have traded. ${ }^{2}$ There is no evidence, however, of profitable trading opportunities based on daily, weekly or monthly aggregate return autocorrelations.

Significant predictability - both economically and statistically - has been identified in longer-horizon stock returns. As mentioned in the previous section, Jegadeesh and Titman (1993) identify profitable trading strategies based on past price momentum over 3- to 12-month intervals. De Bondt and Thaler (1985) find that NYSE stocks identified as the biggest losers (winners) over a period of 3 to 5 years earn, on average, the highest (lowest) market-adjusted returns over a subsequent holding period of the same length of time, a phenomenon that does not seem to disappear when returns are adjusted for size and beta risk. This predictable reversal pattern is often attributed to market "overreaction" in which stock prices diverge from fundamental values because of (irrational) waves of optimism or pessimism before returning eventually to fundamental values. Evidence of this longer-horizon return predictability has been reported in most equity markets around the world. But the significance of negative autocorrelation for long horizon returns is subject to the statistical problems discussed in the next subsection.

\section{Predicting aggregate returns with predetermined observable variables}

The evidence above shows that past returns contain information about expected returns, but they are a noisy signal. A more powerful test uses predetermined explanatory variables that potentially convey more precise information about expected returns. Much recent research documents such predictability using past

\footnotetext{
${ }^{2}$ Lo and MacKinlay (1990) reconcile the paradox of positive portfolio autocorrelations and negative individual stock autocorrelations: because the autocorrelation of portfolio returns is the sum of individual security autocovariances and cross-autocovariances, if the cross-autocovariances are sufficiently large relative to the autocovariances (empirically, they are), then the cross-autocovariances will overshadow the contribution of the autocovariances.
} 
information. An incomplete list of the variables in these studies include expected inflation, yield spreads between long- and short-term interest rates and between low- and high-grade bonds, the dividend-to-price ratio, the earnings-to-price ratio, the book-to-price ratio, and the level of consumption relative to income. Importantly, predictability is stronger when the tests use returns measured over longer horizons, with explanatory power rising to levels of 20 to 40 percent at two to four year horizons. Unfortunately, the increased explanatory power does not come without econometric problems. First, the number of independent observations decreases with the return horizon. To accommodate, researchers use overlapping observations, but the adjustments for standard errors to account for this perform poorly for the relatively small sample periods used in these tests. Second, most of the variables listed above are highly persistent (in contrast to lagged returns used in autocorrelation tests) and their innovations are correlated with return innovations, resulting in biased test statistics. Despite these shortcomings, the level of statistical significance and the robust nature of the results across so many different explanatory variables and across so many worldwide equity markets - strongly argue for a predictable component in aggregate returns.

\section{Patterns in Daily Returns around Weekends}

Consider an exchange where trading takes place Monday through Friday. If the process generating stock returns operates continuously, then Monday returns should be three times the returns expected on each of the other days to compensate for a three-day holding period. Call this the calendar-time hypothesis. An alternative is the trading-time hypothesis: returns are generated only during trading periods and average returns are the same for each of the five trading days in the week. Inconsistent with both hypotheses, stock returns in many countries are negative, on average, on Monday (French (1980)). (In Australia, Korea, Japan and Singapore average returns on Tuesday are negative because of time zone differences relative to the U.S. and European markets.)

What causes the weekend effect? That the pattern exists in so many different markets argues persuasively against many institution-specific explanations. Research has shown that the weekend effect cannot be explained by: differences in settlement periods for transactions occurring on different weekdays; measurement error in recorded prices; market maker trading activity; or systematic patterns in investor buying and selling behavior. That an explanation has been elusive may not be important: in the post-1977 period in the U.S. and in numerous other markets the weekend effect has all but disappeared (see Schwert (2002)).

\section{Patterns in Returns around the Turn of the Year}

Keim (1983) and others document that fifty percent of the annual size premium in the U.S. is 
concentrated in the month of January, particularly in the first week of the year. This finding has been reproduced on many equity markets throughout the world. Blume and Stambaugh (1983) subsequently demonstrated that, after correcting for an upward bias in average returns for small stocks (related to the magnitude of bid-ask spreads), the size premium is evident only in January.

What explains this phenomenon? Two hypotheses rely on the buying and selling behavior of market participants to explain the turn-of-the-year size premium. The first hypothesis attributes the effect to year-end tax-related selling by taxable individual investors of stocks that have declined in price (an attribute shared by many small-cap stocks). In such trades the investor realizes a capital loss which can be used to offset realized capital gains, thereby reducing taxable income. There is much evidence that such tax-related trading occurs at the end of the tax year (which in many countries coincides with the end of the calendar year), but a clear link between such trading and stock return behavior has not been established. A second hypothesis concerns the impact of institutional 'window dressing' at the end of the calendar year - selling off 'loser' stocks that have declined in price (again, typically small-cap stocks) so they don't appear on year-end statements sent to constituent shareholders. Although there is evidence that institutions behave in this fashion, any resulting impact on stock prices is difficult to distinguish from the impact of tax-loss selling. In the end, large bid-ask spreads and high transaction costs for small-cap stocks preclude the profitable exploitation of the short-term return differences between individual small- and large-cap stocks. As a result, the turn-of-the-year size premium continues to be positive in recent years (see figure 2A).

\section{Conclusion}

Recent research in finance has revealed stock price behavior that is inconsistent with the predictions of familiar models. The research on time series predictability, as a whole, is convincing evidence that expected returns are not constant through time. There are reasonable business conditions stories that can account for time variation in expected returns. However, some of the temporal patterns in returns - in particular those relating to calendar turning points - are troubling as they defy economic interpretations.

The evidence on cross-sectional anomalies poses a significant challenge to well-established asset pricing paradigms. Yet despite mounting evidence, there is little consensus on alternative theoretical models. As such, the focus of future research should be on development of such models. Indeed, one of the most significant contributions of this strand of research has been the recognition of potential alternative sources of risk (e.g., risk related to financial distress) and of the potential importance of behavioral models. Importantly, researchers must recognize that the existence of this anomalous evidence does not constitute proof that existing paradigms are 'wrong.' There is the issue of data snooping - much of the empirical research on financial market anomalies is 
predicated on previous research that documented similar findings with the same data. And although many of these effects have persisted for nearly 100 years, this in no way guarantees their persistence in the future. More research is necessary to resolve these issues.

Donald B. Keim 


\section{Bibliography}

Ball, R. 1978. Anomalies in Relationships Between Securities' Yields and Yield-Surrogates, Journal of Financial Economics 6, 103-26.

Banz, R. 1981. The Relationship between Return and Market Value of Common Stock, Journal of Financial Economics 9, 3-18.

Basu, S. 1977. Investment Performance of Common Stocks in Relation to their Price-Earnings Ratio: A Test of the Efficient Market Hypothesis, Journal of Finance, 32, June, 663-682.

Blume, M. and R. Stambaugh. 1983. Biases in Computed Returns: An Application to the Size Effect, Journal of Financial Economics 12, 387-404.

Brennan, M.J. 1970. Taxes, Market Valuation, and Corporate Financial Policy, National Tax Journal 23, 417-27.

Brennan, M.J., T. Chordia and A. Subrhmanyam. 1998. Alternative actor specifications security characteristic, and the cross section of stock returns, Journal of Financial Economics 49, 345-373.

Carhart, M.M. 1997. On the persistence in mutual fund performance, Journal of Finance 52, 57-82.

De Bondt, W. and R. Thaler. 1985. Does the Stock Market Overreact? Journal of Finance 40, 793-805.

De Bondt, W. and R. Thaler 1987. Further Evidence on Investor Overreactions and Stock Market Seasonality, Journal of Finance 42, 557-81.

Fama, E. 1976. Foundations of Finance (Basic Books, New York).

Fama, E. and K. French. 1992. The Cross Section of Expected Stock Returns, Journal of Finance 47, 427-466.

Fama, E. and K. French. 1993. Common Risk Factors in the Returns of Stocks and Bonds, Journal of Financial Economics 33, 3-56.

Graham, B. and D. Dodd. 1940. Security Analysis: Principles and Technique, McGraw-Hill Book Company, Inc., New York.

Hawawini, G., and D. Keim. 2000. The Cross Section of Common Stock Returns: A Review of the Evidence and Some New Findings, in Keim, D.B. and W.T. Ziemba, Security Market Imperfections in Worldwide Equity Markets (Cambridge University Press, 2000).

Jaffe, J., D. Keim and R. Westerfield. 1989. Earnings Yields, Market Values and Stock Returns, Journal of Finance 45, 135-148.

Jegadeesh, N. and S. Titman. 1993. Returns to Buying Winners and Selling Losers: Implications for Stock Market Efficiency, Journal of Finance 48, 65-92.

Keim, D. 1983. Size-Related Anomalies and Stock Return Seasonality: Further Empirical Evidence, Journal of 
Financial Economics 12, 13-32.

Kothari, S., J. Shanken and R. Sloan. 1995. Another Look at the Cross-Section of Expected Stock Returns, Journal of Finance 50, 185-224.

Kuhn, T. 1970. The Stucture of Scientific Revolutions, (University of Chicago Press, Chicago).

Lakonishok, J., A. Schleiffer, and R. Vishny. 1994. Contrarian investment, extrapolation and risk, Journal of Finance 49, 1541-1578.

Litzenberger, R. and Ramaswamy, K. 1979. The Effects of Personal Taxes and Dividends on Capital Asset Prices : Theory and Empirical Evidence, Journal of Financial Economics, 163-195.

Lo, A. and C. MacKinlay. 1990. When are Contrarian Profits due to Stock Market Overreaction, Review of Financial Studies 3, 175-205.

Mehra, R. and E. Prescott. 1985. The equity premium: a puzzle Journal of Monetary Economics 15, 145-161.

Miller, M. and M. Scholes. 1982. Dividend and taxes: Some empirical evidence Journal of Political Economy 90, 1118-41.

Neiderhofer, V. and M.F.M. Osborne. 1966. Market making and reversal on the stock exchange, Journal of the American Statistical Association 61, 897-916.

Reinganum, M. 1981. A Misspecification of Capital Asset Pricing: Empirical Anomalies Based on Earnings Yields and Market Values, Journal of Financial Economics 9, 19-46.

Schwert, G.W. 2003. Anomalies and market efficiency, in G.M. Constantinides, M. Harris and R. Stulz, eds. Handbook of the Economics of Finance (Elsevier Science B.V.). 


\section{Figure 1: The Value and Size Premia (1927-2005)}

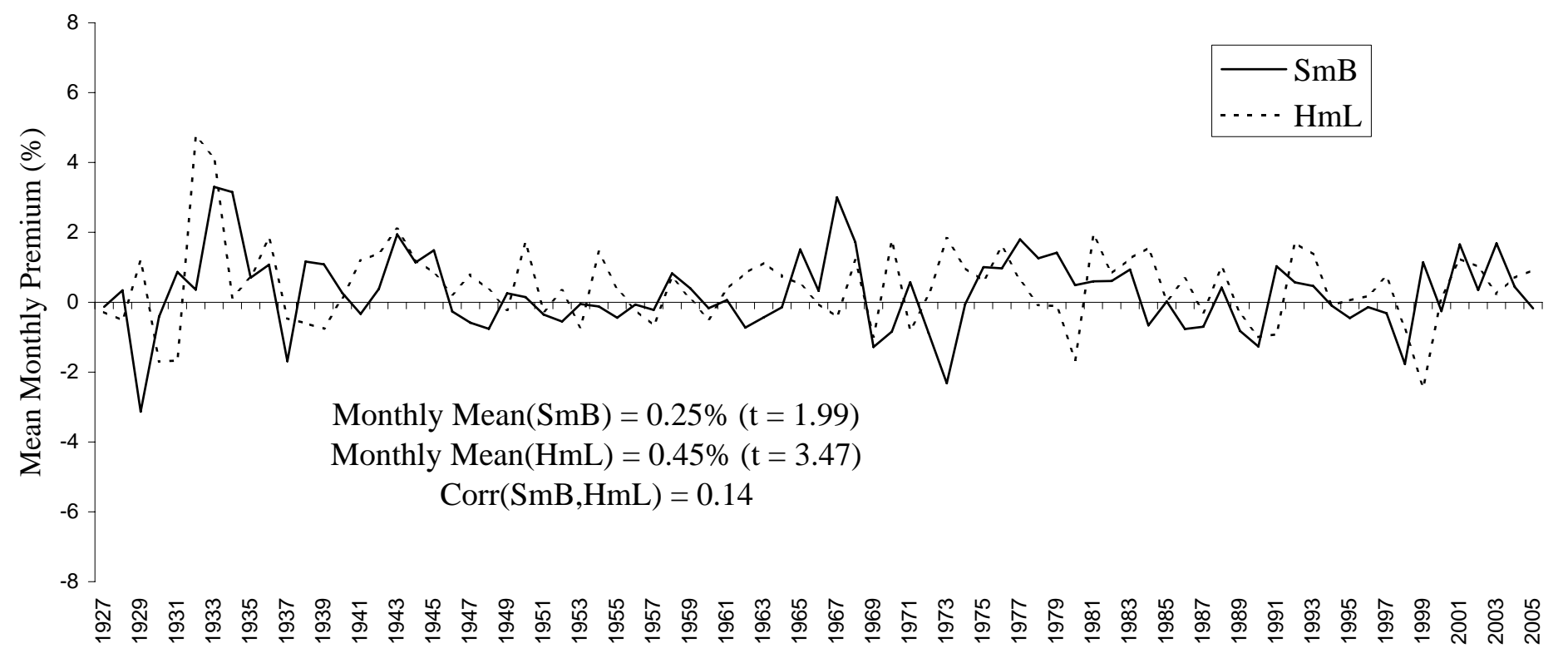




\section{Figure 2A: The Value and Size Premia - January only}

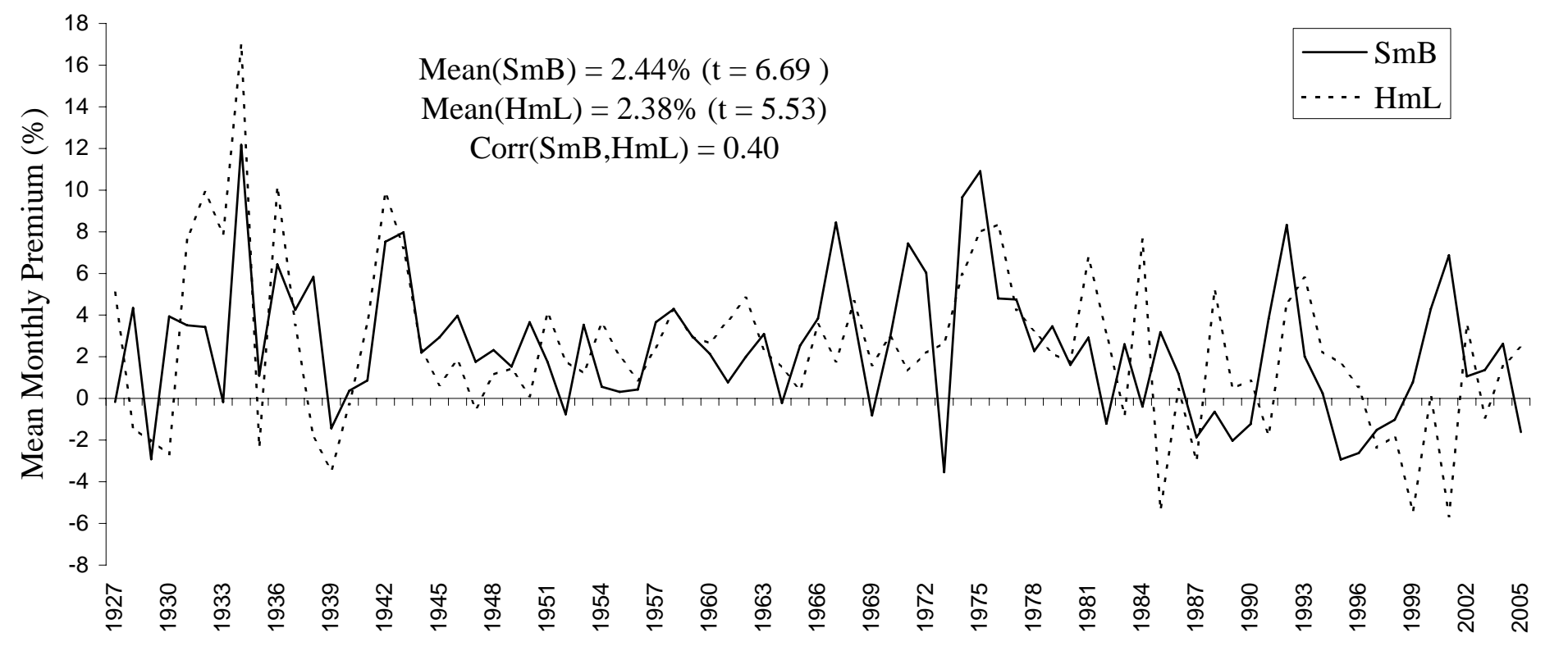

\section{Figure 2B: The Value and Size Premia - Feb to Dec}

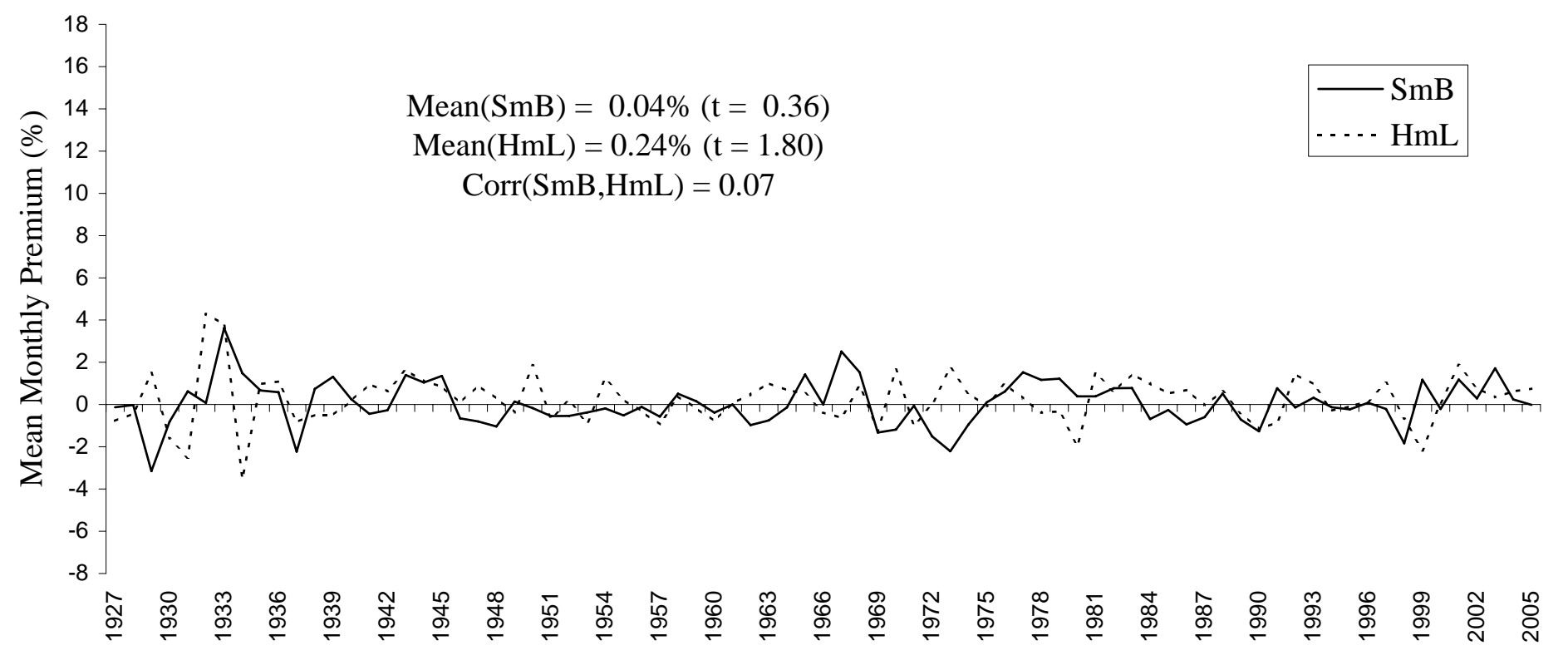

